Article

\title{
Heart Rate Variability in Patients with Essential Hypertension
}

\author{
Rehnuma Tabassum¹, Noorzahan Begum², Sultana Ferdousi ${ }^{3}$, Shelina Begum ${ }^{4}$, TaskinaAli ${ }^{5}$
}

\begin{abstract}
Background: Essential hypertension may be associated with altered cardiovascular autonomic nerve function. Heart Rate Variability (HRV) analysis is an important tool for quantitative measurement of autonomic nerve activity. Objective: To assess the cardiac autonomic nerve function status in essential hypertension by analyzing time domain measures of heart rate variability. Methods: This cross sectional study was carried out in the Department of Physiology, Bangabandhu Sheikh Mujib Medical University from $1^{\text {st }}$ July 2008 to $30^{\text {th }}$ June 2009.For this purpose, 60 hypertensive male patients with age ranged between 40-60 years (group B) were enrolled from the Out Patient Department of Cardiology, BSMMU, Dhaka. Based on treatment received, hypertensive patients were subdivided into group $\mathrm{B}_{1}$ i.e.untreated patients on their $1^{\text {st }}$ day of diagnosis and group $B_{2}$ i.e.patients with antihypertensive therapy. For comparison, 30 age \& sex matched apparently healthy normotensive subjects (group A) were also studied as control group. Time domain measures of Heart Rate Variability (HRV) such as Mean RR intervals, Mean HR, SDNN \& RMSSD were assessed by a Polygraph machine to observe both sympathetic and parasympathetic nerve function status. For statistical analysis of data, Independent sample t-test, One-way ANOVA test, were used as applicable. Results: Mean R-R interval SDNN and RMSSD were significantly $(\mathrm{P}<0.01)$ lower but mean heart rate was significantly $(\mathrm{P}<0.01)$ higher in untreated hypertensive patients than those of normotensive subjects. But differences in all these 4 parameters when compared between control and treated hypertensive patients were found statistically non significant. Conclusion: Impaired cardiac autonomic nerve function characterized by sympathetic overactivity may occur in hypertensive patients.
\end{abstract}

Key words: Mean RR, SDNN,RMSSD, hypertension

J Bangladesh Soc Physiol. 2010 June; 5(1): 1-7 For author affiliations, see end of text.

http://www.banglajol.info/index.php/JBSP

\section{Introduction}

$\mathbf{H}$

ypertension is an emerging health problem in Bangladesh among the cardiovascular diseases. The prevalence rate of hypertension is very high and more than $20 \%$ of the adults in Bangladesh have hypertension. ${ }^{1}$ In essential hypertension no specific medical cause can be found to explain patient's condition. The adverse effects of hypertension principally involve the blood vessels, the retina, the heart, and the kidneys including the central nervous system. ${ }^{2}$

J Bangladesh Soc Physiol. 2010 June; 5(1): 1-7
Evidence from studies of both animals and humans suggested that autonomic nervous system plays a crucial role in the development of hypertension. ${ }^{3}$ The arterial baroreflex mechanism regulates blood pressure through reflex effects on the heart, resistance vessels and renal excretion of sodium and water. ${ }^{4}$

There is evidence that faulty noradrenaline reuptake in the cardiac sympathetic nerves amplify the sympathetic neural signal in essential hypertensive patients. ${ }^{5}$ 
Essential hypertension is treated with drugs which themselves modify the sympathoparasympathetic balance. ${ }^{6,7}$

The heart rate variability analysis is a powerful tool in assessment of the cardiac autonomic nerve function. It is an accurate, reliable, reproducible, yet simple to measure and to process. The source of information for HRV is a continuous beat-bybeat measurement of interbeat intervals. ${ }^{8}$

Time domain method records the heart rate at any point in time or the intervals between successive QRS complex in a continuous ECG record. Common simple time domain variables include the mean normal-to-normal QRS complex (NN) interval and the mean heart rate. Statistical time domain variables include the standard deviation of the NN interval (SDNN) and the square root of the mean squared differences of successive NN intervals (RMSSD).

Several investigators from different countries reported that mean R-R interval was significantly lower and mean heart rate was significantly higher in untreated hypertensive patients than those of healthy control. ${ }^{9-13}$ However, some of the investigators failed to find any significant differences of these parameters between these two groups. ${ }^{11,14}$

Again, a number of studies also documented lower values of SDNN and RMSSD in both untreated and treated hypertensive groups compared to those of normotensive subjects. ${ }^{10-17}$

Hypertension is one of the common cardiovascular problems in our country. Large number of people in our population are affected with hypertension remains unnoticed, which subsequently present with various complications. In addition to metabolic factors, many studies have documented sympathetic hyperactivity as the principal underlying cause for hypertension. Therefore, qualitative measurement of cardiac sympathetic nerve activity along with cardiovagal balance may throw some light on the role of autonomic modulation to develop hypertension and also change in the autonomic activity after treatment with antihypertensive therapy. Therefore, the present study was carried out to observe the autonomic nerve function status in untreated and treated hypertensive patients analyzing HRV by time domain method.

\section{Methods}

This cross sectional study was carried out on 60 male hypertensive patients with age ranged from 40-60 years (group B) in the Department of Physiology, Bangabandhu Sheikh Mujib Medical University from July 2008 to June 2009. Based on treatment, hypertensive patients were subdivided into group $B_{1}$ i.e untreated patients on their $1^{\text {st }}$ day of diagnosis and group $B_{2}$ i.e. patients with antihypertensive medication. For comparison, 30 age, sex and BMI matched apparently healthy normotensive subjects (group A) were also studied. The study group was selected from the Out Patient Department of Cardiology, BSMMU, Dhaka and the control group was selected by personal contact. Both the groups were free from heart diseases, secondary hypertension, diabetes mellitus, renal diseases and psychic disorders.

After selection, the subject was thoroughly informed about the objectives and detail procedure of the study before examination and collection of blood sample. They were encouraged for voluntary participation and allowed freedom to withdraw from the study whenever they like even after participation. If they agreed to enroll to the study, informed written consent was taken from them. For examination the subjects were advised to have their meal by 9:00 pm on the previous night, to remain free from any physical or mental stress, not to take sedatives or any drugs affecting central nervous system and to have a good sleep at night before the day of examination. The subjects were also asked to avoid tea or coffee at breakfast and to attended the Autonomic Nerve Function Test Laboratory in the Department of Physiology of Bangabandhu Sheikh Mujib Medical University

J Bangladesh Soc Physiol. 2010 June; 5(1): 1-7 
between 9:00 to11:00 a.m. on the day of examination. Then the subject was interviewed and detail history regarding personal history, drug history, past medical history was taken for exclusion criteria. Then thorough physical examinations and anthropometric measurement including height and weight were taken.and BMI was calculated. All information were recorded in a prefixed questionnaire. Then he was kept under complete bed rest in supine position for 15-20 minutes in a cool and calm environment. During this period subject was advised not to talk, eat or drink and also not to perform physical or any mental activity, even sleep. Then all preparations for recording of the Heart Rate Variability parameters were made by connecting the channels of ECG and a 5 minutes recording was taken in resting supine position and the HRV parameters were studied by time domain method.

Heart Rate Variability parameters in time domain method such as mean R-R interval, mean Heart Rate, SDNN (standard deviation of N-N interval) and RMSSD (square root of mean squared difference of successive $\mathrm{NN}$ intervals) were assessed by Polygraph (RMS Polyrite D, version 2.2) and for statistical analysis Mann-Whitney U test, Chi-square test and Pearson's correlation coefficient test were done as applicable.

\section{Results}

All the groups were matched for age and BMI (Table I).

The mean resting pulse rate $((\mathrm{p}<0.05)$ systolic (SBP) and diastolic (DBP) blood pressures $(\mathrm{p}<0.001)$ were significantly higher in group $B_{1}$ than those of group $A$ and $B_{2}$. But statistically no significant differences were observed when these parameters were compared between group $A$ and group $B_{2}$. (Table II)

The mean $R-R$ interval was significantly lower $(p<0.01)$ and mean heart rate was significantly $(\mathrm{p}<0.01)$ higher in group $\mathrm{B}_{1}$ compared to group A. But no statistical significant differences were found in these parameters when compared between group $\mathrm{B}_{1}$ and group $\mathrm{B}_{2}$.Again no significant differences were found when compared between $\mathrm{A}$ and $\mathrm{B}_{2}$.

J Bangladesh Soc Physiol. 2010 June; 5(1): 1-7
Table I: Age and BMI in different groups $(\mathrm{n}=90)$

\begin{tabular}{lcc}
\hline Groups & Age (years) & BMI $\left(\mathrm{kg} / \mathrm{m}^{2}\right)$ \\
\hline $\mathrm{A}(\mathrm{n}=30)$ & $48.37 \pm 8.03$ & $24.46 \pm 3.28$ \\
$\mathrm{~B}_{1}(\mathrm{n}=30)$ & $49.77 \pm 7.70$ & $25.37 \pm 2.93$ \\
$\mathrm{~B}_{2}(\mathrm{n}=30)$ & $48.13 \pm 6.24$ & $23.47 \pm 4.16$ \\
\hline
\end{tabular}

Statistical analysis

\begin{tabular}{lll}
\hline Groups & \multicolumn{2}{c}{$\mathrm{p}$ values } \\
\hline${\text { A vs } B_{1} \text { vs B }_{2}{ }^{\mathrm{a}}} 0.651^{\mathrm{ns}}$ & $0.115^{\mathrm{ns}}$ \\
$\mathrm{A}$ vs $\mathrm{B}_{1}{ }^{\mathrm{b}}$ & $0.493^{\mathrm{ns}}$ & $0.263^{\mathrm{ns}}$ \\
$\mathrm{A}$ vs $\mathrm{B}_{2}{ }^{\mathrm{b}}$ & $0.900^{\mathrm{ns}}$ & $0.308^{\mathrm{ns}}$ \\
$\mathrm{B}_{1}$ vs $_{2}{ }^{\mathrm{b}}$ & $0.370^{\mathrm{ns}}$ & $0.05^{\mathrm{ns}}$ \\
\hline
\end{tabular}

Data were expressed as mean $\pm \mathrm{SD}$. Statistical analysis were done by One-way ANOVA ${ }^{\mathrm{a}}$ and Independent sample t-test ${ }^{b}$

BMI $=$ Body Mass Index, $n s=p>0.05, n=$ number of subjects. Group A: Apparently healthy normotensive (control). Group $\mathrm{B}_{\text {: Hypertensive(study group) }}$

$$
\mathrm{B}_{1} \text {-Untreated. } \mathrm{B}_{2} \text { : Treated. }
$$

Table II: Resting Pulse Rate and BP in different groups $(\mathrm{n}=90)$

\begin{tabular}{lccc}
\hline Groups & $\begin{array}{c}\text { Pulse } \\
(\mathrm{bpm})\end{array}$ & $\begin{array}{c}\text { SBP } \\
(\mathrm{mm} \mathrm{of} \mathrm{Hg})\end{array}$ & $\begin{array}{c}\text { DBP } \\
(\mathrm{mm} \text { of Hg) }\end{array}$ \\
\hline $\mathrm{A}(\mathrm{n}=30)$ & $71.23 \pm 7.28$ & $112.67 \pm 10.73$ & $74.43 \pm 8.71$ \\
$\mathrm{~B}_{1}(\mathrm{n}=30)$ & $77.30 \pm 10.22$ & $156.33 \pm 16.18$ & $101.50 \pm 8.63$ \\
$\mathrm{~B}_{2}(\mathrm{n}=30)$ & $74.4 \pm 9.09$ & $117.83 \pm 14.24$ & $78.33 \pm 10.20$ \\
\hline
\end{tabular}

Statistical analysis

\begin{tabular}{|c|c|c|c|}
\hline \multicolumn{2}{|l|}{ Groups } & \multicolumn{2}{|l|}{$P$ values } \\
\hline$A$ vs $B_{1}$ vs $B$ & $2^{\mathrm{a}} 0.036^{*}$ & $0.000 * * *$ & $0.000 * * *$ \\
\hline A vs $B_{1}^{b}$ & $0.010 *$ & $0.000 * * *$ & $0.000 * * *$ \\
\hline A vs $B_{2}^{b}$ & $0.142^{\mathrm{ns}}$ & 0.118 ns & 0.117 ns \\
\hline $\mathrm{B}_{1}$ vs $\mathrm{B}_{2}{ }^{\mathrm{b}}$ & $0.250^{\mathrm{ns}}$ & $0.000 * * *$ & $0.000 * * *$ \\
\hline
\end{tabular}

Data were expressed as mean $\pm \mathrm{SD}$. Statistical analysis were done by One-way ANOVA ${ }^{\mathrm{a}}$ and Independent sample t-test ${ }^{\mathrm{b}} \mathrm{SBP}=$ Systolic blood pressure, $\mathrm{DBP}=$ Diastolic blood pressure.

$* * *=\mathrm{p}<0.001, * *=\mathrm{p}<0.01, *=\mathrm{p}<0.05, \mathrm{~ns}=\mathrm{p}>0.05$, $\mathrm{n}=$ number of subjects. 


\section{Article}

Mean SDNN and RMSSD were significantly $(p<0.001)$ lower in group $B_{1}$ compared to group $A$ and $B_{2}$ except $S D N N$ which is though lower than $\mathrm{B}_{2}$ but statistically not significant. Again these values were significantly $(p<0.001)$ lower in $B_{2}$ than those of group A. (Table-III).

Analysis of Correlations of HRV measures with blood pressure showed that he mean R-R interval was negatively correlated in group $\mathrm{B}_{1}(\mathrm{r}=-0.089)$ but positively correlated in group $\mathrm{A}(\mathrm{r}=+0.233)$ and $\mathrm{B}_{2}(\mathrm{r}=+0.070)$ with SBP.(Table IV).
HRV in Hypertension

But with DBP, this parameter showed negative $(r=-0.137$, $r=-0.151)$ correlation in group $\mathrm{B}_{1}$ and $\mathrm{B}_{2}$ whereas positive $(\mathrm{r}=+0.015)$ correlation in group A.(Table V).

Again, the mean HR showed positive correlation in group $\mathrm{B}_{1}(\mathrm{r}=+0.074)$ and negative correlations in group $A(r=-0.029)$ and $B_{2}(r=-0.283)$ with SBP(Table IV). Again, with DBP it was positively $(\mathrm{r}=+0.244)$ correlated in group $\mathrm{B}_{1}$ and $\mathrm{A}(\mathrm{r}=$ $+0.137)$ but negatively correlated( $r=-0.079)$ in group $\mathrm{B}_{2}$ (Table V). All these relationships were statistically nonsignificant.

Table III : Time domain measures of HRV in different groups ( $\mathrm{n}=90$ )

\begin{tabular}{lllll}
\hline Groups & $\begin{array}{l}\text { Mean R-R } \\
\text { interval }(\mathrm{Sec})\end{array}$ & $\begin{array}{l}\text { Mean HR } \\
(\mathrm{bpm})\end{array}$ & $\begin{array}{l}\text { SDNN } \\
(\mathrm{ms})\end{array}$ & $\begin{array}{l}\text { RMSSD } \\
(\mathrm{ms})\end{array}$ \\
\hline $\mathrm{A}(\mathrm{n}=30)$ & $0.9 \pm 0.15$ & $71.13 \pm 7.37$ & $65.58 \pm 17.07$ & $32.33 \pm 4.92$ \\
$\mathrm{~B}_{1}(\mathrm{n}=30)$ & $0.79 \pm 0.2$ & $76.97 \pm 9.12$ & $49.82 \pm 6.38$ & $20.03 \pm 2.63$ \\
$\mathrm{~B}_{2}(\mathrm{n}=30)$ & $0.8 \pm 0.15$ & $72.70 \pm 8.75$ & $51.99 \pm 7.70$ & $23.37 \pm 3.11$ \\
\hline
\end{tabular}

Statistical analysis

\begin{tabular}{lllll}
\hline Groups & \multicolumn{3}{c}{ p values } \\
\hline $\mathrm{A}_{\text {vs B }}{ }_{1}$ vs B $_{2}{ }^{\mathrm{a}}$ & $0.007^{* *}$ & $0.025^{*}$ & $0.000^{* * *}$ & $0.000^{* * *}$ \\
$\mathrm{~A}$ vs B ${ }_{1}^{\mathrm{b}}$ & $0.003^{* *}$ & $0.008^{* *}$ & $0.000^{* * *}$ & $0.000^{* * *}$ \\
$\mathrm{~A}$ vs B ${ }_{2}^{\mathrm{b}}$ & $0.019^{*}$ & $0.456^{\mathrm{ns}}$ & $0.000^{* * *}$ & $0.000^{* * *}$ \\
$\mathrm{~B}_{1} \mathrm{vs} \mathrm{B}_{2}{ }^{\mathrm{b}}$ & $0.648^{\mathrm{ns}}$ & $0.070^{\mathrm{ns}}$ & $0.239^{\mathrm{ns}}$ & $0.000^{* * *}$ \\
\hline
\end{tabular}

Data were expressed as mean \pm SD.

Statistical analysis were done by One-way ANOVA $^{\mathrm{a}}$ and Independent sample t-test ${ }^{\mathrm{b}}$

$\mathrm{R}-\mathrm{R}$ = Interval between successive QRS complex (sec), HR = Heart rate.

SDNN=Standard deviation of NN interval.

NN = Intervals between adjacent QRS complexes from SA node depolarization.

RMSSD=Square root of mean squared differences between adjacent NN intervals, $\mathrm{ms}=$ millisecond, $\mathrm{ms}^{2}=$ squared millisecond.

$* * *=\mathrm{p}<0.001, *=\mathrm{p}<0.05 \mathrm{~ns}=\mathrm{p}>0.05, \mathrm{n}=$ number of subjects.

Table IV: Correlation of heart rate variability measures with SBP in different groups ( $\mathrm{n}=90)$.

\begin{tabular}{lcccccc}
\hline HRV measures & \multicolumn{7}{l}{ Groups } & \multicolumn{3}{c}{} \\
\cline { 2 - 6 } & $\mathrm{A}$ & $\mathrm{B}$ & $\mathrm{B}$ & $\mathrm{B}_{2}$ & \\
& $\mathrm{r}$ & $\mathrm{r}$ & $\mathrm{p}$ & $\mathrm{r}$ & $\mathrm{p}$ \\
\hline Time domain: & & & & & \\
Mean R-R interval & +0.233 & $0.215^{\mathrm{ns}}$ & -0.089 & $0.639^{\mathrm{ns}}$ & +0.070 & $0.712^{\mathrm{ns}}$ \\
Mean HR & -0.029 & $0.881^{\mathrm{ns}}$ & +0.074 & $0.698^{\mathrm{ns}}$ & -0.283 & $0.129^{\mathrm{ns}}$ \\
\hline
\end{tabular}


HRV in Hypertension

Article

Table V : Correlations of heart rate variability measures with DBP in different groups $(\mathrm{n}=90)$.

\begin{tabular}{lcccccc}
\hline HRVmeasures & \multicolumn{2}{c}{ Groups } & & & \\
\cline { 2 - 6 } & $\mathrm{A}$ & & $\mathrm{B}$ & & $\mathrm{B}_{2}$ & \\
& $\mathrm{r}$ & $\mathrm{p}$ & $\mathrm{r}$ & $\mathrm{p}$ & $\mathrm{r}$ & $\mathrm{p}$ \\
\hline Time domain: & & & & & \\
Mean R-R interval & +0.015 & $0.935^{\mathrm{ns}}$ & -0.137 & $0.470^{\mathrm{ns}}$ & -0.151 & $0.426^{\mathrm{ns}}$ \\
Mean HR & +0.137 & $0.471^{\mathrm{ns}}$ & +0.244 & $0.194^{\mathrm{ns}}$ & -0.079 & $0.677^{\mathrm{ns}}$ \\
\hline
\end{tabular}

Statistical analyses were done by Pearson's correlation coefficient (r) test.

$\mathrm{SBP}=$ Systolic Blood Pressure

$\mathrm{DBP}=$ Diastolic Blood Pressure

$\mathrm{ns}=\mathrm{p}>0.05, \quad \mathrm{n}=$ number of subjects

\section{Discussion}

In the present study, findings of the time domain HRV parameters in healthy control group were almost similar to those reported by the various investigators from different countries ${ }^{10-14}$ and also from our country $18-20$

In this study, the mean resting pulse rate and resting systolic and diastolic blood pressures were found significantly higher in untreated hypertensive patients in comparison to that of healthy normotensive and treated hypertensive groups. But these values showed no statistically significant difference between healthy normotensive and treated hypertensive groups

Similar type of findings was also reported by the various investigators from different countries $^{3,11,13,14,21}$

Significantly lower mean R-R interval and significantly higher mean heart rate were observed in untreated hypertensive patients than those of healthy control. Similar findings were also reported by researchers from different countries $^{9-13}$

Again, in this study, the mean values of SDNN and RMSSD were found significantly lower in untreated hypertensive patients compared to healthy control. Similar significant change in these two parameters in hypertensive patients were also reported by ${ }^{10-17}$

J Bangladesh Soc Physiol. 2010 June; 5(1): 1-7
Again, in untreated hypertensive patients mean R-R interval was negatively correlated whereas mean HR was positively correlated with both SBP and DBP. The correlations were statistically not significant. No report was available to compare these findings.

Investigators suggested that essential hypertension is commonly neurogenic and attributed to sympathetic overdrive. They also suggested that several factors are responsible for the changes of autonomic nerve function activities associated with essential hypertension. Presence of autonomic nerve dysfunction may leads to arterial hypertension. 9,11,14,22

More over in essential hypertension, there is increased rate of sympathetic nerve firing and also increased density of sympathetic innervations. Furthermore, co-transmission of adrenaline in cardiac sympathetic nerve along with impaired removal of noradrenaline from the synaptic cleft might also be the contributory factors for sympathetic over activity in essential hypertension. $^{5}$

Again some investigators recommended that $\mathrm{b}$ adrenergic mediated vasodilation might have some contribution in the sympathetic overdrive in essential hypertension ${ }^{23-25}$

In the present study, decreased values of SDNN,RMSSD indicating decreased HRV and 
lower RR interval and higher HR are suggestive of decrease vagal modulation and higher sympathetic activity in essential hypertension. This is further supported by negative correlation of RR interval and positive correlation of HR with systolic and diastolic blood pressure.

\section{Conclusion}

From the result of this study it can be concluded that impaired cardiac autonomic nerve function characterized by sympathetic overactivity may occur in hypertensive patients.

\section{Author affiliations}

1. *Rehnuma Tabassum,Assistant professor, Department of Physiology,International Medical College, Tongi, Gazipur. Email:rehnuma.15@gmail.com.

2. Noorzahan Begum, Professor, Department of Physiology,Bangabandhu Sheikh Mujib Medical University (BSMMU), Bangladesh. Email: noorzahanbeg@yahoo.com.

3. Sultana Ferdousi, Assistant Professor, Department of Physiology, Bangabandhu Sheikh Mujib Medical University (BSMMU), Bangladesh. Email: sferdousiratna@gmail.com.

4. Shelina Begum, Professor, Chairman Department of Physiology, Bangabandhu Sheikh Mujib Medical University (BSMMU),Bangladesh.

5. Taskina Ali, Assistant Professor Department of Physiology, Bangabandhu Sheikh Mujib Medical University (BSMMU), Bangladesh. Email:taskinadr @gmail.com.

*For correspondence

\section{References}

1 Shahriar I, Haque Z, Momen A. Patterns of Antihypertensive Drugs Used in Two Postgraduate Institutions. Journal of Dhaka National Medical college and Hospital. 2008; 13(1):41-44.

2. Boon NA, Fox KA. Diseases of the cardiovascular system. In:Davidson's Principles and Practice of Medicine. Edwards CRW, Bouchier IAD, Haslett C, Chilvers ERE editors.Edinburgh: Elsivier science Limited; 2002.p. 388-391.

3. Wu J, Lu F, Yang Y, Lin T, Chen J, Wu C, HuangY, Chang C. Epidemiological Study on the Effect of Pre hypertension and Family History of Hypertension on Cardiac Autonomic Function. J Am Coll Cardiol.2008; 51:1896-1901.

4. Julius S. Autonomic nervous system dysregulation in human hypertension. Am J Cardiol. 1991; 67: 3B-7B.
5. Esler M, Rumantir M, Kaye D, Jennings G, Hastings J, Socratous F, Lambert G. Sympathetic nerve biology in essential hypertension.Clin Exp Pharmacol Physiol. 2001; 28(12):986-9.

6. Pagani M, Lucini D. Autonomic dysregulation in essential hypertension: Insight from heart rate and arterial pressure variability. Auton Neurosci. 2001; 90: 76-82.

7. Guzzetti S, Piccaluga E, Casati R, et al. Sympathetic predominance in essential hypertension: A study employing spectral analysis of heart rate variability. J Hypertension. 1988; 6:711-17.

8. Heart Rate Variability Testing.[Internet ]2008 [cited May 2008] Available from:http:///www.docgeorge.com.

9. Singh JP, Larson MG, Tsuji H, et al. Reduced heart rate variability in new-onset hypertension. Insights into pathogenesis of hypertension. The Framingham Heart study. Hypertension. 1998; 32:293-97.

10. Kaftan AH and Kaftan O.QT Intervals and Heart Rate Variability in Hypertensive Patients. Jpn Heart J.2000; 41(2):173-182.

11. Pavithra P, Madanmohan, Mithun R, Jomal M, Nandeesha H. Heart Rate Variability in Middle Aged Men with New-Onset Hypertension. Ann of Noninvasive Electrocardiol.2008; 13(3):242-48.

12. Sevre K, Johan D, Lefrandt, Nordby G, Os I, Mulder M, Reinold OB, Gans, Rostrup M, Smit JA. Autonomic Function in Hypertensive and Normotensive Subjects: Importance of Gender. Hypertension. 2001; 37:1351-56.

13. Mussalo H, Vanninen E, Ikäheimo R, Laakso M, Länsimies E, Hartikainen J. Heart rate variability and its determinants in patients with severe or mild essential hypertension. Clin Physiol. 2008; 21(5):594-604.

14. Prakash ES, Madanmohan, Sethuraman KR, et al. Cardiovascular autonomic regulation in subjects with normal blood pressure, high-normal blood pressure and recent-onset hypertension. Clin Exp Pharmacol Physiol. 2005; 32:488-94.

15. Huikuri HV, Ylitalo A, Pikkujamasa SM, et al. Heart rate variability in systemic hypertension. Am J Cardiol. 1996; 77:1073-77.

16. Pikkujamsa SM, Huikuri HV, Airaksinen KE, Rantala AO, Kauma H, Lilja M, Savolainen MJ, Kesaniemi YA. Heart rate variability and baroreflex sensitivity in hypertensive subjects with and without metabolic

J Bangladesh Soc Physiol. 2010 June; 5(1): 1-7 
HRV in Hypertension

Article

features of insulin resistance syndrome. Am J Hypertens. 1998; 11:523-31.

17. Chakko S, Mulingtapang RF, Huikuri HV, Kessler KM, Materson BJ, Myerburg RJ. Alterations in heart rate variability and its circadian rhythm in hypertensive patients with left ventricular hypertrophy free of coronary artery disease. Am Heart J. 1993;126:1364-72.

18. Kabir MR. Study on heart rate variability in patients with hyperthyroidism. [MPhilThesis] [Dhaka (Bangladesh)]: Bangabandhu Sheikh Mujib Medical University.2008.

19. Ahmed M. Assessment of Cardiac Autonomic Nerve Function Status by Heart Rate Variability in Hypothyroid Patients. [MPhil Thesis] [Dhaka (Bangladesh)]: Bangabandhu Sheikh Mujib Medical University. 2009 .

20. Mithun S. Comparative study of Cardiac Autonomic Nerve Function Status by Heart Rate Variability between sedentary and heavy workers. [MPhilThesis] [Dhaka (Bangladesh)]: Bangabandhu Sheikh Mujib Medical University. 2009 July.
21. SrinivasaJ, Bhat MR, Adhikari P. Comparative Study of Heart Rate Variability (HRV) during Deep Breathing in Normotensive and Hypertensive Subjects. JIACM. 2002; 3(3): 266-70.

22. Lucini D, Mela GS, Malliani A, et al. Impairment in cardiac autonomic regulation preceding arterial hypertension in humans: Insights from spectral analysis of beat-by-beat cardiovascular variability. Circulation. 2002; 106:2673-79.

23. Feldman RD. Defective venous beta-adrenergic response in borderline hypertensive subjects is corrected by a low sodium diet. J Clin Invest.1990; 85: 647-52.

24. Naslund T., D. J. Silberstein, W. J. Merrell, J. H. Nadeau, and A. J. J. Wood. Low sodium intake corrects abnormality in receptor mediated arterial vasodilation in patients with hypertension: correlation with -receptor function in vitro. Clin Pharmacol Ther. 1990; 48: 87-95.

25. Stein CM, Nelson R, Deegan R, He H, Wood M, Wood AJJ. Forearm beta adrenergic receptormediated vasodilation is impaired, without alteration of forearm norepinephrine spillover, in borderline hypertension. J Clin Invest.1995; 96: 579-85. 